\title{
Analysis of Boron Removal for Reverse Osmosis, lon Exchange, and Capacitive Deionization
}

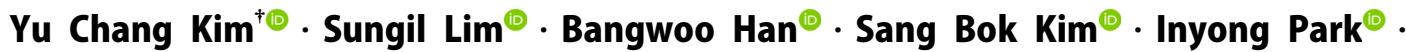 \\ Gunhee Lee ${ }^{\circledast}$. Dae Hoon Park ${ }^{\circledast}$. Keejung Hong ${ }^{\odot}$
}

Korea Institute of Machinery and Materials, Department of Environmental Machinery, Republic of Korea

(Received August 31, 2021; Revised October 13, 2021; Accepted October 28, 2021)

Objectives: This article provides a comparative analysis of boron removal for brackish water reverse osmosis (BWRO), boron selective ion exchange (IX), or capacitive deionization (CDI) processes. Permeate of 1st-Pass RO process has to be post-treated for additional boron removal. Hence, we experimentally analyzed the performance of boron removal and specific energy consumption (SEC) of three aforementioned processes and investigated whether the processes are suitable for 2 nd pass process of RO desalination.

Methods: Raw feed water was prepared using $\mathrm{NaCl}$ and $\mathrm{B}(\mathrm{OH})_{3}$. Semi-pilot scale $\mathrm{RO}$ and IX systems (over 1 $\mathrm{m}^{3} / \mathrm{hr}$ capacity) and bench scale CDI system (over $2.5 \mathrm{~L} / \mathrm{min}$ ) were tested for performance comparison. Boron concentration was measured using Azomethine- $\mathrm{H}$ method for feed and product water. Energy consumption was monitored by using power quality analyzer.

Results and Discussion: Each process has its own operating conditions. The RO process required high $\mathrm{pH}$ of feed water for high boron removal rate, the IX process was operated below breakthrough point considering adsorption capacity of boron selective resin, and the CDI process didn't remove boron because chloride ion has higher ion selectivity for carbon electrode than boron. In terms of SEC, the pressure-driven RO process showed the highest SEC among three processes. The CDI process based on electrical adsorption of carbon electrode showed a considerable energy consumption as well. On the other hand, the IX process was operated at low energy consumption because its removal is just based on adsorption-desorption mechanism.

Conclusions: The RO and CDI processes have received a lot of attention as leading and emerging technology while the IX process was regarded as a stubborn process because of regeneration of resin and its several segmentalized steps. However, we found that the IX process has a better performance for boron removal and energy consumption.

Keywords : boron removal, desalination, reverse osmosis, ion exchange, capacitive deionization 


\title{
연구논문
}

\section{역삼투, 이온교환, 축전식 탈염 공정의 보론 제거 성능 분석}

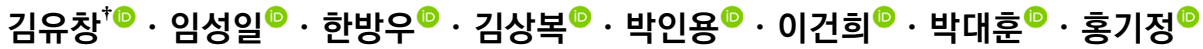 \\ 한국기계연구원 환경기계연구실
}

목적 : 본 연구는 기수용 역삼투, 이온교환, 축전식 탈염 공정의 보론 제거 성능을 비교 분석하기 위해서 수행하였 다. 역삼투식 해수담수화 공정에서는 본처리 공정인 역삼투 공정의 투과수내에 있는 보론을 추가적으로 더 제거해 야 한다. 따라서, 세 공정의 보론 제거 성능과 에너지 소비량을 실험적으로 분석하여 상호 비교하였으며, 이를 통 해 이 공정들이 해수담수화 공정의 생산수를 추가 처리하는 2nd pass (2차 통과) 공정으로 사용이 가능한지 여부를 분석하였다.

방법: 실험에 사용할 원수는 $\mathrm{NaCl}$ 과 $\mathrm{B}(\mathrm{OH})_{3}$ 를 이용하여 제조하여 사용하였으며, 역삼투 공정과 이온교환 공정은 소형 파일럿 규모(생산수량 $1 \mathrm{~m}^{3} / \mathrm{hr}$ 이상), 축전식 탈염 공정은 벤치 규모 $(2.5 \mathrm{~L} / \mathrm{min}$ 이상)의 시스템을 실험에 사용 하였다. 각 공정의 원수와 처리수의 보론 농도를 Azomethine-H 방법으로 분석하였으며, 시스템의 소비 전력을 전 력 분석기로 측정하여 에너지 소비량을 분석하였다.

결과 및 토의: 공정마다 보론을 제거하기 위한 운전조건이 다르다. 역삼투 공정의 경우 원수의 $\mathrm{pH}$ 를 충분히 올려 야 제거율이 좋아지며, 이온교환 공정의 경우 보론 선택성 수지(resin)의 흡착용량을 고려하여 파과점(breakthrough point) 이내에서 운전하여야 하며, 축전식 탈염 공정의 경우 보론이 다른 이온과 혼합되어 있으면 전극에 의한 이 온 선택성 때문에 연속식 흐름을 갖는 시스템으로는 처리가 어려웠다. 각 공정의 에너지 소비는 가압형 공정인 기 수용 역삼투 공정이 가장 컸으며, 축전식 탈염 공정도 탄소전극이 소비하는 전기량이 적지 않았다. 최근 역삼투와 축전식 탈염 공정이 관심을 많이 받는 것은 사실이지만 실제 보론 제거 성능이나 에너지 소비 측면에서는 보론 선 택성 수지를 이용하는 이온교환 공정이 우수한 성능을 보이는 것으로 분석되었다.

결론: 이온교환 공정은 재생용 약품 폐수가 발생하고 운전이 쉽지 않다는 단점이 있다. 하지만 보론 제거와 에너 지 소비 측면에서는 이온교환 공정이 기수용 역삼투와 축전식 탈염 공정보다 좋은 성능을 보였다. 물론 생산수의 사용처, 환경 및 에너지, 타 공정과의 연계성, 하이브리드 구성 등 다양한 측면에서 고려할 필요가 있다.

주제어: 보론 제거, 해수담수화, 역삼투, 이온교환, 축전식 탈염

\section{1. 서론}

최근 극단적인 가뭄과 집중호우가 세계 곳곳에서 빈번하게 발생하고 있다. 이와 같은 강수의 강도와 변동성의 극심한 증 가는 지구 온난화에 따른 전 지구적인 기후 변화의 영향 때문 인 것으로 알려져 있다. 따라서, 이제는 기후 변화에 따른 지 표수 고갈 및 극심한 가뭄과 같은 위기에 적극적으로 대처하 기 위해 다양한 대체 수자원 개발을 추진해 나가야 한다. 대체 수자원을 확보하는 기술 중 해수담수화와 하폐수 재이용 기술 은 기존의 수처리 기술보다는 에너지 소비량이 큰 기술이어서 탄소중립을 위해 저에너지 해수담수화 기술이 요구되고 있 다. ${ }^{1)}$ 중동 지방의 경우 오래전부터 해수담수화를 통한 수자원 확보가 전반적으로 이루어져 왔지만 다른 지역은 그렇지 못하
였다.

해수담수화에는 대표적으로 증발식과 역삼투식이 있지만, 역삼투식이 증발식에 비해 에너지소비량(specific energy consumption, $\mathrm{SEC}$ )이 낮기 때문에 세계적으로 설치가 확대되 고 있다. 역삼투식의 경우, 이온은 배제하고 물만 통과시키는 분리막과 고압펌프를 사용하는 가압방식이기 때문에 여전히 펌프에 의한 에너지 소비가 크다. 특히, 대부분의 역삼투 방식 의 플랜트의 경우 해수용 분리막(seawater reverse osmosis membrane, SWRO)과 기수용 분리막(brackish water reverse osmosis membrane, BWRO)을 two-pass (2회 통과 방식)로 구 성하여 사용하기 때문에, 1 st pass (1차 통과)에서 해수 원수 (feed water)를 가압하는 펌프 이외에도 2nd pass (2차 통과)에 서 1st pass (1차 통과)의 투과수(permeate)를 가압해주는 펌프 
가 추가로 필요하여 에너지 사용량이 적지 않다. 보통 이렇게 분리막을 two-pass (2회 통과 방식)로 구성하여 사용하는 이유 는 single-pass (1회 통과)로 처리해서는 생산수의 요구 수질을 맞추기 어렵기 때문이다. ${ }^{2)}$ 특히 보론(boron)의 경우 다른 이온 과는 달리 분리막의 배제율이 낮아 single-pass (1회 통과) 구 성으로는 충분히 제거가 되지 않아 two-pass (2회 통과) 방식 이 필요하다. 참고로 분리막 공정에서 전단 베셀(vessel)의 농 축수를 후단 베셀의 공급수로 사용하는 경우 two-stage (2단) 공정이라 하며, 전단 베셀의 생산수를 후단 베셀의 공급수로 사용하는 경우 two-pass (2회 통과) 공정이라고 한다.

$\mathrm{TDS}$ 가 $35,000 \mathrm{mg} / \mathrm{L}$ 인 해수 내의 보론 농도는 대략 4.5 $\mathrm{mg} / \mathrm{L}$ 이며, $1 \mathrm{st}$ pass 투과수의 보론농도는 대략 $0.7 \sim 1.2 \mathrm{mg} / \mathrm{L}$ 이다. ${ }^{3)}$ 대개 two-pass 역삼투 공정을 거쳐야 보론 농도 0.3 $0.5 \mathrm{mg} / \mathrm{L}$ 의 투과수를 얻을 수 있다. 보론에 대한 WHO 농도 기준은 여러 번의 개정을 거쳐 현재는 $2.4 \mathrm{mg} / \mathrm{L}$ 이하이지만, 담수화된 생산수가 사용되는 용도(음용, 경작용, 산업용 등)가 나라마다 다르기 때문에 중동지역에서도 나라마다 다른 기준 을 적용하고 있다. ${ }^{4)}$ 예를 들어, 사우디아라비아, 쿠웨이트, $\mathrm{UAE}$ 는 각각 $0.5,1,2.4 \mathrm{mg} / \mathrm{L}$ 이하를 기준으로 정해 운영하고 있다. 작물에 따라 보론 농도에 대한 민감도가 달라 경작용으로 사용시 생산수내 보론 농도가 보통 더 낮아야 한다.

해수담수화시 보론을 제거하기 위해 사용되는 공정으로는 위에서 언급한 BWRO 공정 이외에도 보론만 선택적으로 흡 착하는 수지(boron selective resin, BSR)를 사용하는 이온교환 공정(ion exchange, IX)이 있다. ${ }^{5)}$ 두 공정의 차이는 BWRO 공정의 경우 염소와 보론 등의 모든 이온이 제거의 대상이 되지만, IX공정의 경우 보론만 제거의 대상이라는 점이다. 분 리막을 사용하는 BWRO 공정은 가압식 공정인데 반해, BSR 수지가 채워진 IX 공정의 경우 비가압식 흡착 공정이다. 또한, $\mathrm{BWRO}$ 분리막은 세척이 자주 필요하지 않은데 반해, BSR 수 지의 경우 흡착용량이 떨어지면 화학약품을 투입해 재생을 해 줘야 한다. 최근에는 축전식 탈염 기술(capacitive deionization, $\mathrm{CDI}$ 도 2nd pass $\mathrm{BWRO}$ 공정을 대체하기 위한 기술로 관심 을 받고 있다. ${ }^{6)} \mathrm{CDI}$ 공정은 전하를 띠는 원자나 이온 형태의 분자들이 전기이중층의 원리를 이용하는 탄소전극에 흡착되 어 제거되는 공정이다. 전위차가 양극과 음극에 주어지면 수 중에 있는 양이온과 음이온은 정전기력에 의해 각각 음극과 양극으로 이동하여 흡착된다. 다공성 탄소 전극에 이온들이 흡착되어 탄소전극의 흡착능력이 떨어지면 운전을 멈추고 역 전위를 가해 흡착된 이온을 탈착시켜 전극의 흡착능력을 회복 시켜야 한다. 따라서 흡착되는 동안에는 탈염이 진행되지만 탈착되는 동안에는 고농도 농축액이 배출되며 전극의 재생이 진행된다. CDI 공정은 원수의 TDS 농도가 $5000 \mathrm{mg} / \mathrm{L}$ 이하일 때 적용이 가능하다고 알려져 있다.

본 연구에서는 상기에서 언급한 세 개의 공정인 BWRO 공 정, $\mathrm{BSR} \mathrm{IX}$ 공정, $\mathrm{CDI}$ 공정이 해수담수화 공정의 2nd pass로
적합한지 여부를 분석하기 위해 각 공정의 보론 제거 성능을 실험적으로 분석하였다. 또한, 보론 제거 성능과 함께 가장 중요한 성능 지표인 에너지 소비량(SEC)을 실험적으로 분석 하였다. 이러한 실험적 분석과 함께 각 공정의 장단점을 설계 및 운영 측면에서 분석하여 비교하였다.

\section{2. 실험방법}

\section{1. 보론 측정}

원수 및 처리수의 보론 농도는 두 가지 방식(자동 및 수동) 으로 측정되었다. 두 가지 방식 모두 발색시약 Azomethine-H 를 사용하여 흡광도를 측정하는 측정 방식이고, ${ }^{7)}$ 시료 샘플링, 발색시약 투입, 혼합, 측정, 세정 등이 자동인지 수동인지만 다를 뿐이다. 자동과 수동 측정장치로는 각각 엔바이로라이저 (EnviroLyzer, AppliTek, Belgium)와 분광광도계(Spectrophotometer DR-6000, Hach, USA)를 사용하였으며, 사용되는 파 장(wavelength)은 각각 $405 \mathrm{~nm}$ 와 $414 \mathrm{~nm}$ 였다. Azomethine-H 를 이용하는 방법의 측정 가능 범위는 $0.05 \sim 5.00 \mathrm{mg} / \mathrm{L}$ 이다. IX 시스템에만 자동 측정기를 설치하였으며, 다른 시스템의 경우 정해진 시간 간격에 따라 샘플링하여 분석하였다.

\section{2. 소비에너지 측정}

세 공정의 에너지 소비량 $\left(\mathrm{SEC}, \mathrm{kWh} / \mathrm{m}^{3}\right)$ 은 전력품질 분석기 (Energy and Power Quality Analyzer 435 series II, Fluke, $\mathrm{USA}$ )의 전류 및 전압 프로브를 측정하고자 하는 시스템에 연결하여 시스템이 정상운전 중일 때 소비하는 전력 $(\mathrm{kW})$ 을 측정하여 구하였다.

\section{3. 실험장치}

실험에 사용한 시스템 중 기수용 역삼투(BWRO) 시스템과 이온교환수지(IX) 시스템은 자체 설계 및 제작하였으며, 축전 식 탈염(CDI) 시스템은 국내 기업에서 실험용으로 판매되는 장치를 구입하여 사용하였다. 세 시스템 모두 전도도센서, 유 량센서, 압력센서, 온도센서들이 배관에 설치되어 있어 연속 적으로 모니터링이 가능하였다. Fig. 1은 실험에 사용한 세 종 류의 시스템에 대한 사진이다.

기수용 역삼투(BWRO) 시스템에는 기수용 역삼투 엘리먼트 (BW30-4040, DOW, USA) 4개를 직렬로 배열하였으며, 소형 시스템에 적합한 플런저 펌프(Cat pumps 1541, Minneapolis, USA)를 사용하였다.

이온교환수지(IX) 시스템은 보론만 선택적으로 흡착 제거 하는 수지(Amberlite PWA10, DOW, USA)가 채워진 두 개의

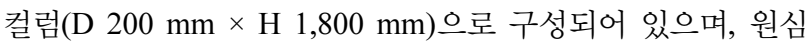
펌프(CRN 1-4, Grundfos, USA)를 사용하였다.

축전식 탈염(CDI) 시스템은 양/음이온 교환막이 코팅된 탄 소전극 96장이 적층 된 셀(E100, 시온텍, Korea)과 최대 전류 

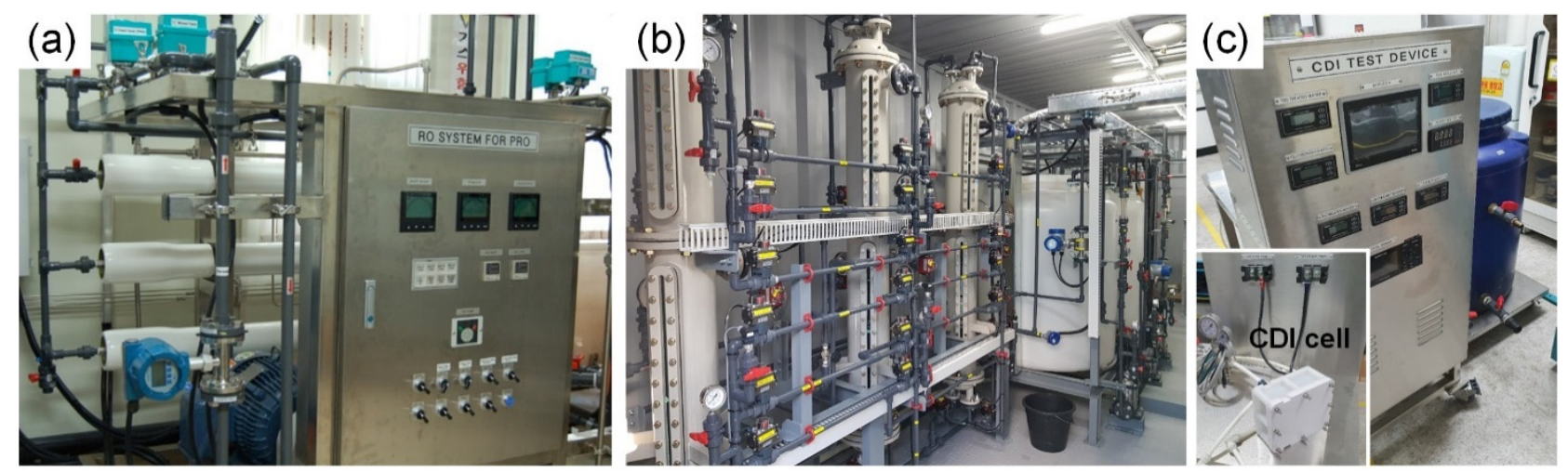

Fig. 1. Images of experimental (a) BWRO, (b) IX, and (c) CDI systems.

$15 \mathrm{~A}$ 와 평균 전압 $1.5 \mathrm{~V}$ 를 인가할 수 있는 직류전원장치로 구성되었으며, 저유량의 소형 원심펌프(TPH2T2KS, Walrus, Taiwan)를 사용하였다.

\section{4. 실험방법}

실험에 사용한 원수는 염화나트륨 $(\mathrm{NaCl})$ 농도 $200 \mathrm{mg} / \mathrm{L}$, 보론 농도 $1 \mathrm{mg} / \mathrm{L}$, 수온 25 도로 조절하였다. BWRO공정과 $\mathrm{CDI}$ 공정에 대해서는 원수의 $\mathrm{pH}$ 를 8 이상으로 조정하기 위해 가성소다 $(\mathrm{NaOH})$ 를 주입했기 때문에 총용존고형물(TDS)의 농도는 약 $220 \mathrm{mg} / \mathrm{L}$ 까지 상승하였다. CDI공정은 보론 농도 $1 \mathrm{mg} / \mathrm{L}$ 에 대해서는 제거율에 변화가 전혀 없어 $2 \mathrm{mg} / \mathrm{L}$ 의 보 론 농도에 대해서 실험을 수행하였다.

$1 \mathrm{mg} / \mathrm{L}$ 의 보론이 포함된 원수를 처리하여 $0.5 \mathrm{mg} / \mathrm{L}$ 의 보론 이 포함된 생산수를 얻기 위해 BWRO 공정은 $\mathrm{pH} 8.5$, 운전압 력 $10.6 \mathrm{bar}$, 공급유량 $2 \mathrm{~m}^{3} / \mathrm{hr}$ 로 운전하였으며, 이때 회수율은 $50 \%$, 멤브레인의 플럭스는 $34.5 \mathrm{~L} / \mathrm{m}^{2} \mathrm{hr}$ 였다. 회수율에 대한 영향을 분석하기 위해 공급수 유량을 $2.86,2.0,1.54 \mathrm{~m}^{3} / \mathrm{hr}$ 로 조정하였으며, 이에 대해 회수율을 $35,50,65 \%$ 로 변화시켜 생산수 $1 \mathrm{~m}^{3} / \mathrm{hr}$ 을 얻었다. 공급수 유량을 변화시켜 회수율을 변화시켰기 때문에 압력에는 큰 변화가 없었으며, 각각의 압 력은 $10.8,10.6,10.5 \mathrm{bar}$ 였다.

$0.5 \mathrm{mg} / \mathrm{L}$ 의 보론이 포함된 생산수를 얻기 위해 IX 공정은 운전유량 $1 \mathrm{~m}^{3} / \mathrm{hr}$ 로 운전하였는데, 이는 비유량(specific flow rate) $20 \mathrm{BV} / \mathrm{hr}$, 선속도(linear flow velocity) $31.8 \mathrm{~m} / \mathrm{hr}$, 체류시 간(empty bed contact time, EBCT) 3.4 분에 해당하며, 이 때 회수율은 재생 시 소비되는 수량을 고려하면 약 $95 \%$ 였다. 수 지의 재생은 역세, 산 주입, 저속 수세, 염기 주입, 저속 수세, 고속 수세의 순서로 진행하며, $3.6 \% \mathrm{HCI}(73.5 \mathrm{~L} / \mathrm{hr}, 40 \mathrm{~min})$ 과 $2 \% \mathrm{NaOH}(127.4 \mathrm{~L} / \mathrm{hr}, 30 \mathrm{~min})$ 로 하였다.

$\mathrm{CDI}$ 공정은 탄소전극으로 구성된 셀을 정전위 방식 $(1.5 \mathrm{~V}$ 인가)으로 운전하였고, 흡착을 위해서는 양전위, 탈착을 위해 서는 역전위(polarity reversal)를 가하였다. 흡착을 위한 운전 시간은 170 초, 탈착을 위한 운전시간은 120 초였으며, 유량은 $2.5,3.5,4.5 \mathrm{~L} / \mathrm{min}$ 로 변화시켰다.

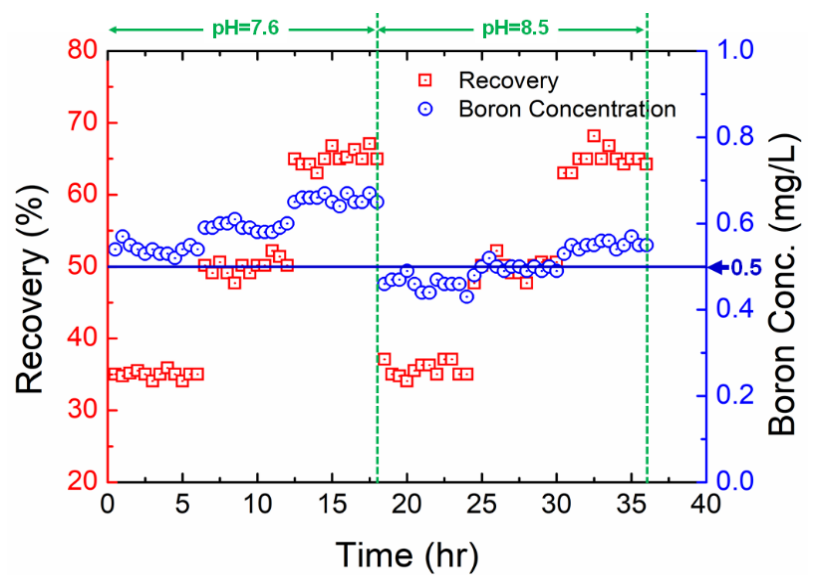

Fig. 2. Effect of recovery change for boron concentration of permeate in BWRO system.

\section{3. 결과 및 고찰}

\subsection{BWRO 공정의 결과}

역삼투막은 대부분의 이온에 대해 보통 $99 \%$ 이상의 배제율 을 가지는데 특이하게도 보론에 대해서만 $60 \sim 80 \%$ 정도의 배 제율을 보인다. ${ }^{8)}$ 이는 보론이 $\mathrm{pH} 7$ 이하에서는 전하를 띠지 않는 붕산 $\left(\mathrm{B}(\mathrm{OH})_{3}\right)$ 으로 대부분 존재하고, $\mathrm{pH} 8$ 이상이 되어 야 음이온인 보레이트 $\left(\mathrm{B}(\mathrm{OH})_{4}{ }^{-}\right)$로 바뀌기 때문이다. 양이온도 음이온도 아닌 붕산의 상태로 존재하면 역삼투막으로 제거가 잘 되지 않는다. 따라서 $\mathrm{RO}$ 공정으로 보론을 처리하기 위해서 는 $\mathrm{pH}$ 를 높여 붕산 $\left(\mathrm{B}(\mathrm{OH})_{3}\right)$ 을 보레이트 $\left(\mathrm{B}(\mathrm{OH})_{4}{ }^{-}\right)$형태로 바 꿔야 처리효율을 올릴 수 있다.

Fig. 2는 원수의 $\mathrm{pH}$ 가 7.6과 8.5 에 대해, 회수율을 35,50 , $65 \%$ 로 조절하였을 경우 생산수의 보론 농도를 보여주고 있 다. 회수율을 올리면 생산수의 보론 농도도 올라가는 경향을 보였다. 즉, 제거율이 떨어졌다. 물론 $\mathrm{pH}$ 7.6에서는 회수율을 낮춰도 생산수의 보론 농도가 $0.5 \mathrm{mg} / \mathrm{L}$ 이하로 낮아지지 않 았다. 이에 반해 $\mathrm{pH} 8.5$ 에서는 회수율을 $50 \%$ 이하로 낮추면 생산수의 보론 농도가 $0.5 \mathrm{mg} / \mathrm{L}$ 이하로 낮아졌다. 따라서 $\mathrm{BWRO}$ 공정으로 생산수의 보론 농도를 맞추기 위해서는 $\mathrm{pH}$ 


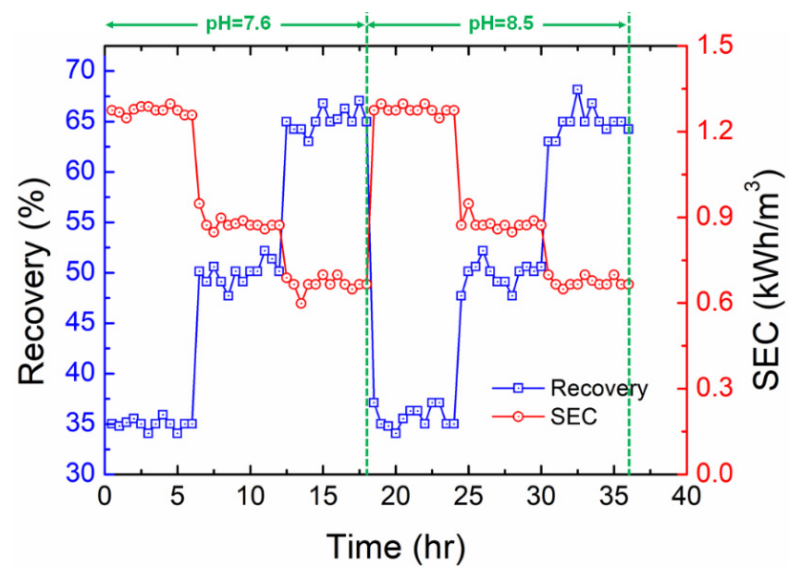

Fig. 3. Effect of recovery change for specific energy consumption (SEC) in BWRO system.

조절과 함께 회수율 조절도 필요한 것으로 확인되었다. 이때 염배제율은 대략 $97.5 \%$ 였다.

Fig. 3은 위의 BWRO 공정을 운전하는 동안 회수율 변화에 따른 에너지 소비량(SEC)을 보여주고 있다. SEC는 역삼투 시 스템이 운전되는 동안에 전력 $(\mathrm{kW})$ 과 생산수의 유량 $\left(\mathrm{m}^{3} / \mathrm{hr}\right)$ 을 측정하여 구하였다. 에너지 소비량은 $\mathrm{pH}$ 변화와는 상관이 없 으며, 회수율이 올라가면 에너지 소비량은 낮아졌다. 이는 회 수율을 올리면 소비되는 전력도 어느 정도는 증가는 하지만 생산수의 유량이 상대적으로 더 늘어나기 때문이다. BWRO 의 $\mathrm{SEC}$ 는 $\mathrm{pH} 8.5$ 와 회수율 $50 \%$ 일때 $0.87 \mathrm{kWh} / \mathrm{m}^{3}$ 이었다.

\subsection{IX 공정의 결과}

$\mathrm{BSR}$ 수지를 이용하는 IX 공정은 보론에 선택흡착성이 있는 수지의 관능기(N-methyl-d-glucamine, NDMG)와 보론이 킬 레이트 화합물을 형성하여 수지에 흡착제거되는 원리를 이용 한다. ${ }^{5)}$ 보론 선택성이라는 말이 의미하는 바와 같이 다른 이 온들은 제거되지 않는다. 수지가 채워진 베드(fixed bed)를 통

(a)

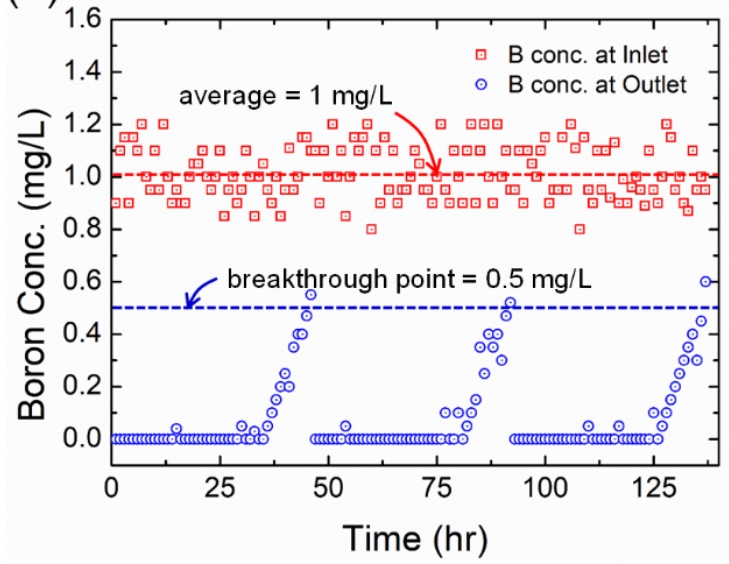

해 원수를 통과시키면 원수 내의 보론은 수지에 흡착되고 일 정시간 운전하여 수지의 흡착용량에 가까워지거나 미리 정한 파과점(breakthrough point)에 도달하면 운전을 멈추고 재생을 하여야 한다.

컬럼 베드 시스템의 중요한 운전인자는 비유량(specific flow rate)과 접촉시간(EBCT)이지만, 본 연구에서는 비유량과 접 촉시간의 영향은 따로 분석하지 않았다. 즉, 비유량과 접촉시 간은 최적조건인 $20 \mathrm{BV} / \mathrm{hr}$ 와 $3.4 \mathrm{~min}$ 으로 고정하여 실험을 수행하였다. 대신, 두 보론 농도(1과 $2.4 \mathrm{mg} / \mathrm{L})$ 에 대한 성능을 조사하였다. 보통 이온교환이나 선택적 흡착 공정의 경우 소규 모 벤치스케일 실험장치에서는 파과곡선(breakthrough curve) 을 통해 동적 성능을 확인하지만, ${ }^{9}$ 본 연구와 같이 실험장치 의 규모가 커지면 파과곡선 전체를 얻는 대신 운전단계에서 재생단계로 넘어가는 시점인 파과점(breakthrough point)까지 만 운전하여 성능을 확인한다. 본 연구에서도 파과점의 농도 를 $0.5 \mathrm{mg} / \mathrm{L}$ 로 설정하여 유출수의 보론 농도가 이 농도에 도 달하면 운전을 멈추고 수지 재생을 한 후 운전하였다.

Fig. 4는 시간에 따른 처리수(생산수)의 보론 농도 변화를 보여주고 있다. Fig.4(a)와 (b)는 각각 원수의 보론 농도가 1 과 $2.4 \mathrm{mg} / \mathrm{L}$ 인 경우 처리수의 보론 농도의 변화를 나타낸 것 이다. 원수의 보론 농도가 일정한 값을 보이지 않는 이유는 고농도 보론 용액을 원수 탱크에 정량 펌프로 주입하면서 실 험을 수행했기 때문이다. 아마 정량펌프가 맥동을 가지고 있 고, 교반시에 탱크내 농도가 완전히 균일하지 않기 때문인 것 으로 보인다. 원수 내의 보론 농도가 낮고 파과점의 보론 농도 도 낮기 때문에 운전 시작 후 30 여 시간까지는 처리수에서 보론이 검출되지 않았다. 30 여 시간이 지난 후에 유출수의 보 론 농도가 조금씩 증가하기 시작하였으며 파과점의 농도인 $0.5 \mathrm{mg} / \mathrm{L}$ 에 도달할 때까지만 운전을 하였다. A컬럼과 B컬럼 을 교대로 운전하였으며 파과점에 도달하면 운전을 멈추고 재생을 하였다. 원수의 보론 농도가 $1 \mathrm{mg} / \mathrm{L}$ 인 경우 운전가능

(b)

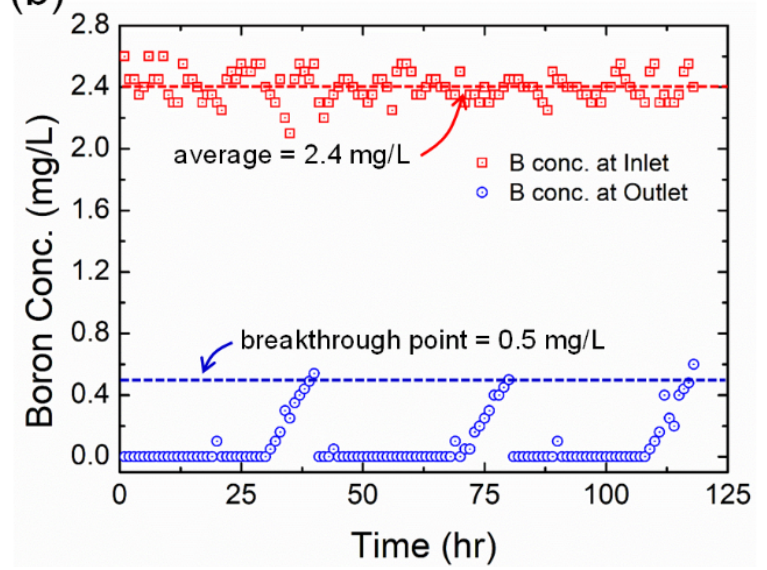

Fig. 4. Boron concentration of effluent as a function of time in IX system. (a) influent boron concentration of $1 \mathrm{mg} / \mathrm{L}$ and (b) $2.4 \mathrm{mg} / \mathrm{L}$. 


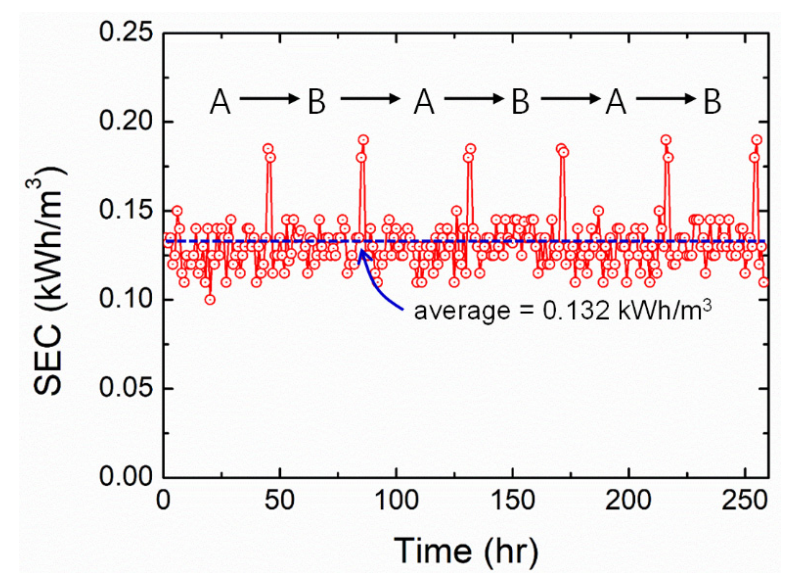

Fig. 5. Specific energy consumption (SEC) as a function of time in IX system.

시간은 대략 45 46 시간인데 반해, 원수의 보론 농도 2.4 $\mathrm{mg} / \mathrm{L}$ 에 대해서는 운전가능시간이 38 40 시간으로 줄어드는 것을 확인하였다.

Fig.5는 IX 시스템의 에너지 소비량(SEC)을 보여주고 있다. 운전하는 동안의 소비 전력과 생산수 유량을 측정하여 구하였 다. 주기적으로 에너지 소비량이 증가한 이유는 한 수지 컬럼 이 파과점에 도달하였을 경우 멈추고 재생 과정이 진행되며 다른 컬럼의 운전이 시작되어 약 3 시간 동안은 운전과 재생 이 동시에 진행되기 때문이다. 평균 $\mathrm{SEC}$ 는 약 $0.132 \mathrm{kWh} / \mathrm{m}^{3}$ 이었다.

\section{3. $\mathrm{CDI}$ 공정의 결과}

Fig. 6(a)는 유량 변화에 따른 CDI시스템의 원수, 처리수, 농축수의 TDS 농도 변화를 보여주고 있다. 흡착이 진행되어 처리수가 발생하는 시간은 170 초, 탈착이 진행되어 농축수가 발생하는 시간은 120 초로 설정하였으며, $1.5 \mathrm{~V}$ 의 전압을 셀에 인가하였다. $\mathrm{pH}$ 9로 조절된 원수의 TDS 농도는 대략 220 $\mathrm{mg} / \mathrm{L}$, 보론 농도는 $2.2 \mathrm{mg} / \mathrm{L}$ 였다. 운전 유량은 $2.5,3.5,4.5$
$\mathrm{L} / \mathrm{min}$ 으로 조정하였는데 유량이 작아짐에 따라 처리수의 TDS 농도가 낮아지는 것을 볼 수 있다. 즉, 체류시간이 길어 지면 제거율이 증가하였다. 두 전극면 사이의 채널을 통과하 며 이온들이 전극으로 이동하여 흡착되어 제거되는 것이기 때문에 유량이 빠르면 체류시간이 짧아져 제거가 덜 이루어져 처리수의 농도가 높은 것으로 보여진다. ${ }^{10)}$

Fig.6(b)는 유량 변화에 따른 보론 농도의 변화를 보여주고 있다. 놀랍게도 CDI 공정으로는 보론이 거의 제거되지 않았 다. 즉, 처리수의 보론 농도는 원수의 보론 농도와 큰 차이를 보이지 않았다. 유량에 따라 차이는 있지만 $2.5 \mathrm{~L} / \mathrm{min}$ 의 유량 에서 다른 이온 $\left(\mathrm{Na}^{+}, \mathrm{Cl}^{-}\right)$들은 $90 \%$ 이상의 배제율을 보이는데 반해, 보론의 경우 배제율 계산이 무의미할 정도로 제거가 되 지 않았다. 이와 같이 보론이 $\mathrm{Na}^{+}$와 $\mathrm{Cl}^{-}$이온과는 달리 제거되 지 않는 이유는 이온의 전하량에 따라 흡착시 선택성이 작용 하기 때문인 것으로 보여진다. ${ }^{11)}$ 다시 말해 $\mathrm{B}(\mathrm{OH})_{4}{ }^{-}$와 $\mathrm{Cl}^{-}$가 같이 존재하면 $\mathrm{Cl}^{-}$가 우선적으로 흡착된다는 의미이다. 음이 온인 보레이트 이온은 염소이온처럼 1가의 음이온이지만 상 대적으로 염소이온의 선택성이 보레이트 이온의 선택성보다 크기 때문인 것으로 분석된다. 또한, 원수내에 염소보다 보론 이 상대적으로 적은 양 들어있어 선택성에 영향을 주는 것으 로 생각된다. 물론 유량을 아주 낮춰 체류시간을 훨씬 크게 운전하거나 $\mathrm{NaCl}$ 없이 보론만 용존된 원수를 사용하면 제거 가 된다.

Fig.7(a)는 유량 변화시 소비전력의 변화를 보여주고 있다. 흡착과 탈착이 진행됨에 따라 같은 패턴으로 소비전력이 변화 되며, 운전 유량이 감소하면 소비전력이 일정하게 하락하였 다. 흡착과 탈착 교대시 역전위가 인가되는데 순간적으로 셀 에 전기 공급이 끓어지며 한 싸이클시 두번의 최소 소비전력 값이 나타나게 된다. 그림에서 위쪽 선이 최대 소비전력값을, 아래쪽 선이 최소 소비전력값을 나타낸다. 이 최소 소비전력 값은 시스템의 기본적인 요소들인 펌프, 제어반, 계측용 $\mathrm{HMI}$ 등이 일정하게 소비하는 전력인 것을 알 수 있다. 벤치스케일

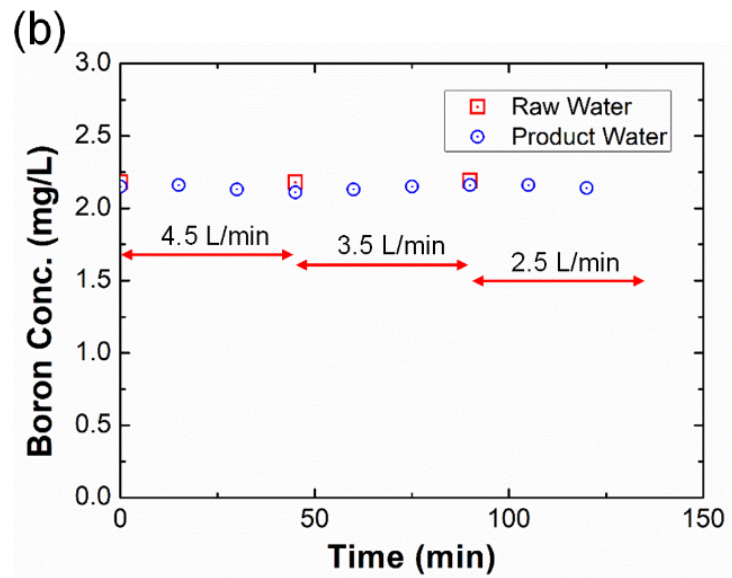

Fig. 6. Effect of flow rate for (a) TDS and (b) boron concentration in CDI system.

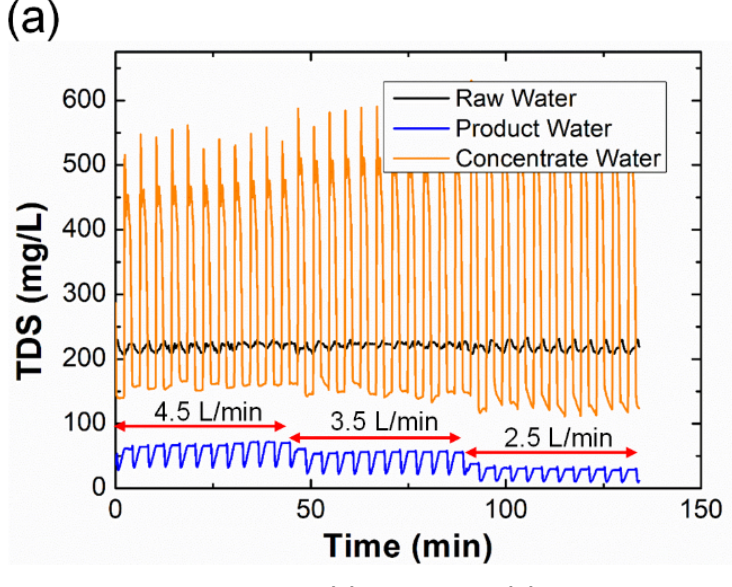


(a)

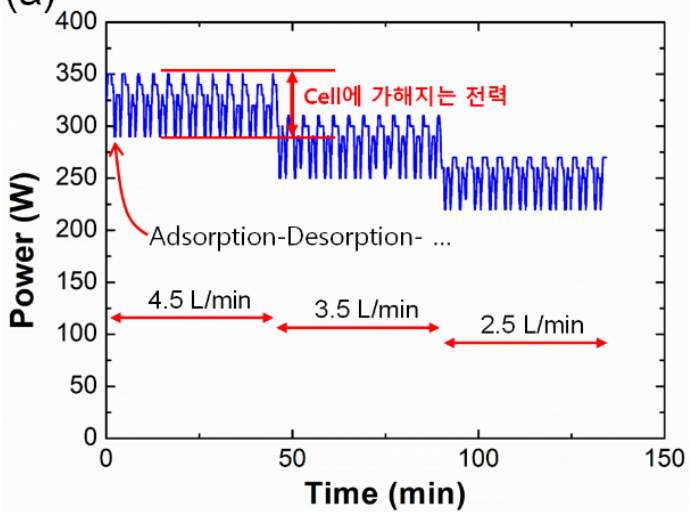

Fig. 7. Effect of flow rate for (a) power consumption and

시스템이기 때문에 셀의 크기보다 펌프와 제어반 등의 크기가 더 커 전기에너지 소비가 부속설비에서 많이 발생하였던 것으 로 보인다.

Fig. 7(b)는 유량의 변화에 따른 에너지 소비량(SEC)과 염 배제율(salt rejection)의 변화를 보여주고 있다. 이 에너지 소 비량은 소비 전력과 생산수 유량(탈착시 생산 중지 고려)을 계측하여 얻은 것이다. 앞의 보론 제거 IX 시스템의 경우 두 개의 컬럼이 사용되어 운전과 재생이 동시에 진행되는 경우 전력 사용이 늘어나는 것을 확인했던 것처럼, $\mathrm{CDI}$ 시스템의 경우도 연속적으로 정수하기 위해서 두 개의 셀을 사용하면 에너지 소비량은 더 늘어날 것이다. 실제 현장에서 사용하기 위해서는 교대로 운전이 되도록 시스템을 구축해야 한다.

\section{4. 공정 비교}

Fig. 8은 세 공정에 의한 TDS와 보론의 제거율을 비교한 것이다. $\mathrm{BWRO}$ 공정의 경우 유입수의 $\mathrm{pH}$ 조절과 회수율 조절 을 통해 생산수의 보론 농도를 $0.5 \mathrm{mg} / \mathrm{L}$ 로 맞추는 것(제거율 $50 \%$ )이 가능하였다. 하지만, 대형 플랜트의 $2 \mathrm{nd} \mathrm{pass}$ 는 대부 분 회수율을 80 90\%로 운전하기 때문에 목표 보론 농도를 맞추기 위해서는 보론 제거에 더 특화된 분리막을 사용하고 보론이 음이온인 보레이트 상태로 다 전환되도록 $\mathrm{pH}$ 를 더 높 여줘야 한다. IX 공정은 파과점의 농도를 얼마로 정하는냐에 따라 생산수의 평균 농도가 달라진다. IX 공정의 특성상 재생 직후에는 보론을 거의 전부 흡착제거(제거율 $100 \%$ )했지만 파 과점에 도달할 때까지 처리수의 보론 농도는 점차 올라갔다 (파과점 도달시 제거율 $50 \%$ ). 파과점의 농도인 $0.5 \mathrm{mg} / \mathrm{L}$ 에 도달할 때까지 생산된 생산수의 평균농도는 $0.1 \mathrm{mg} / \mathrm{L}$ 이하였 다. $\mathrm{CDI}$ 공정의 경우 보레이트 $\left(\mathrm{B}(\mathrm{OH})_{4}^{-}\right)$형태의 보론이 $\mathrm{Cl}^{-}$ 이온과 혼합되어 있고 상대적으로 적은 농도라서 앞의 두 공 정과는 달리 원수에 포함된 보론이 이온 선택성의 영향으로 거의 제거되지 못하였다(제거율 $2 \%$ 미만).

물 생산성은 회수율을 통해 판단이 가능하다. 운전조건에 따라 차이는 있지만 BWRO공정은 막표면에서 교차흐름 형태

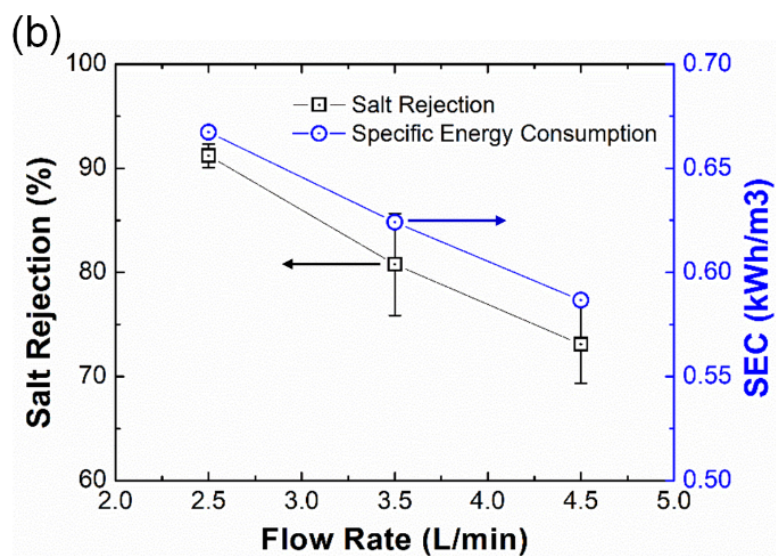

(b) specific energy consumption (SEC) in CDI system.

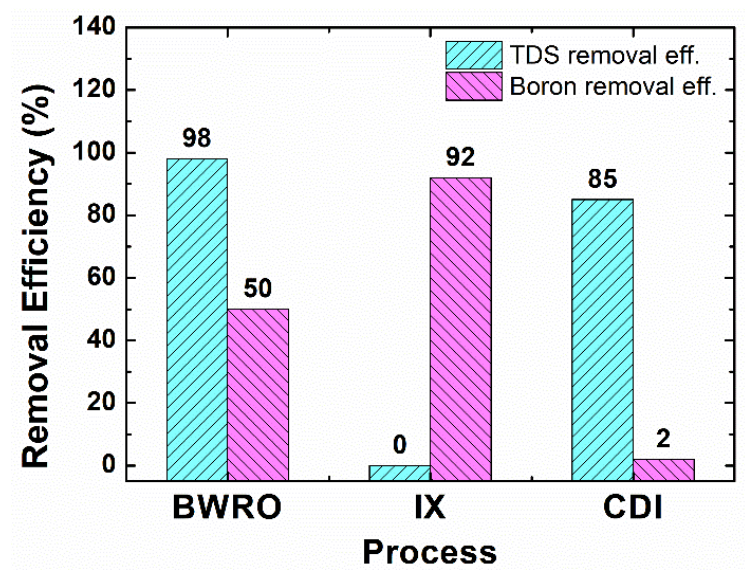

Fig. 8. Removal efficiency of TDS and boron in BWRO, IX, and $C D I$ processes.

로 운전되기 때문에 대형플랜트에서는 80 $90 \%$, 본 연구와 같 은 소형플랜트에서는 $50 \sim 60 \%$ 의 회수율을 보였다. IX공정은 공급된 원수가 수지가 채워진 컬럼을 통과하면 보론이 흡착되 어 처리가 되기 때문에 운전단계로만 보면 $100 \%$ 의 회수율을 가지지만 재생단계에서 소비되는 물까지 고려하면 92 97\%의 회수율을 보였다. $\mathrm{CDI}$ 공정은 흡착을 위해 운전하는 시간만큼 탈착에도 비슷한 시간이 소요되기 때문에 $50 \sim 60 \%$ 의 회수율 을 보였다. 물론 흡착과 탈착 시 유량을 변화시켜 약간의 회수 율 조절은 가능하다.

Fig. 9에서 비교된 에너지 소비량(SEC)의 경우, 본 연구에서 실험에 사용한 $\mathrm{CDI}$ 시스템이 다른 시스템들(RO와 IX)과 동 일한 생산용량을 가지지 않으며 각 시스템에서 사용되는 펌 프, 제어반, 계측 $\mathrm{HMI}$ 시스템 등의 사양과 크기가 달라 각 시스템의 에너지 소비량을 정확히 나타낸다고 볼 수는 없다. 이처럼 여러 공정들의 성능을 정확하게 비교하기 위해서는 동일한 조건(원수 및 처리수 수질조건, 처리용량 등)에서 운전 이 되어야 한다. 동일한 조건이 어렵다면 최대한 비슷한 조건 이 필요하다. 하지만, 성능비교를 위해 처리용량이 동일한 세 가지 파일럿 시스템들을 제작하기는 현실적으로 어렵기 때문 


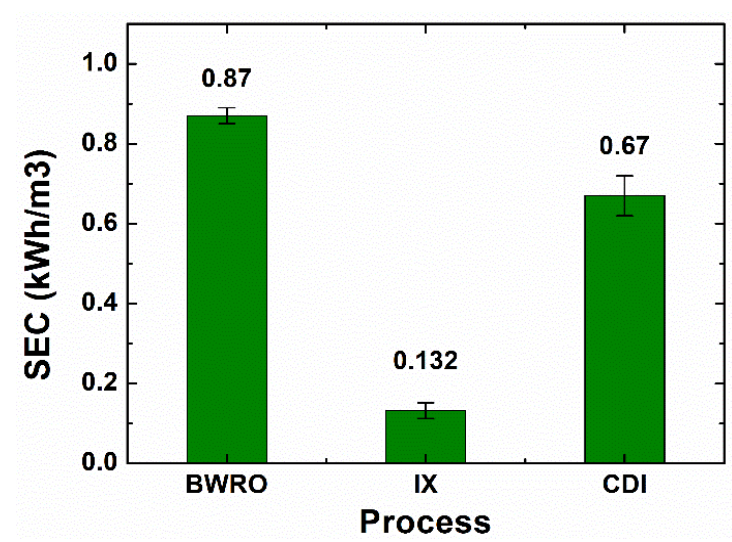

Fig. 9. Comparison of the measured specific energy consumption for BWRO, IX, and CDI systems.

에, Table 1과 같이 펌프의 소비 전력을 계산하여 본 연구의 분석 결과를 보완하였다. 펌프가 소비하는 전력은 아래와 같 은 식을 통해 계산이 가능하다. ${ }^{12)}$

$$
W_{\text {pump }}=\left(P_{\text {out }}-P_{\text {in }}\right)_{\text {pump }} \times Q_{\text {pump }} \times 1 / \eta_{\text {pump }} \times 1 / \eta_{\text {motor }} \times
$$

위 식에서 각각의 단위는 다음과 같다. $W$ (전력)는 $\mathrm{kW}, P$ (압 력)는 $\mathrm{bar}, Q$ (용량)는 $\mathrm{m}^{3} / \mathrm{hr}, \eta$ (효율)는 \%/100이며, $1 / 36$ 은 환
산 계수이다. $\mathrm{BWRO}$ 와 $\mathrm{IX}$ 공정과는 달리, $\mathrm{CDI}$ 는 셀 전극에 전기를 $15 \mathrm{~A} / \mathrm{m}^{2}$ 정도 인가해 줘야하며 이는 에너지 소비량으 로 대략 $0.5 \mathrm{kWh} / \mathrm{m}^{3}$ 정도 되는 것으로 보고되고 있다. ${ }^{6}$ 결국 전기로 구동하는 셀의 소비 전력과 펌프의 소비 전력을 함께 고려하면 $\mathrm{CDI}$ 공정은 저에너지 공정은 아닌 것으로 분석되 었다.

본 연구는 단 기간 동안 소형 시스템들을 운전하여 평가한 것이기 때문에, 인건비, 유지관리비용, 기타비용 등이 포함되 는 운영비를 정확히 계산하는 것이 어렵다. 또한, $\mathrm{CDI}$ 시스템 의 경우 아직은 태동기술이기 때문에 대부분의 연구가 초소형 셀을 사용한 연구에 한정되어 있다. 하지만, 기존 문헌에 보고 (Table2)된 대형 BWRO와 IX 플랜트의 비용을 참고하면 두 공정에 대해서는 대략적인 운영비 비교가 가능하다. ${ }^{13)}$

\section{4. 결 론}

1) 보론 제거 성능 측면에서 보면 검토된 세 공정중 IX 공정 이 가장 우수한 것으로 보인다. 유입수의 $\mathrm{pH}$ 를 조절하지 않아 도 되며 수지가 파과점 농도에 도달하기 전까지 안정적인 보 론 제거율을 얻을 수 있었다. 다만, 보론만 선택적으로 제거하 기 때문에 염소 이온의 추가 제거는 어려우며 재생을 위해

Table 1. Comparison of calculated specific energy consumptions of pumps in BWRO, IX and CDI systems.

\begin{tabular}{cccccccc} 
& $\begin{array}{c}\text { Recovery } \\
(\%)\end{array}$ & $\begin{array}{c}\text { Feed flow rate } \\
\left(\mathrm{m}^{3} / \mathrm{hr}\right)\end{array}$ & $\begin{array}{c}\text { Product flow rate } \\
\left(\mathrm{m}^{3} / \mathrm{hr}\right)\end{array}$ & $\begin{array}{c}\text { Pump outlet } \\
\text { pressure } \\
(\text { bar })\end{array}$ & $\begin{array}{c}\text { Pump inlet } \\
\text { pressure } \\
(\text { bar })\end{array}$ & $\begin{array}{c}\text { Energy } \\
\text { Consumption } \\
(\mathrm{kW})\end{array}$ & $\begin{array}{c}\text { Specific Energy } \\
\text { Consumption } \\
\left(\mathrm{kWh} / \mathrm{m}^{3}\right)\end{array}$ \\
\hline BWRO & 90 & 55.56 & 50 & 10.5 & 0.2 & 28.38 & 0.568 \\
IX & 95 & 52.63 & 50 & 1 & 0.2 & 2.09 & 0.042 \\
CDI & 60 & 83.33 & 50 & 1 & 0.2 & 3.31 & 0.066 \\
\hline
\end{tabular}

*Assumption: The product flow rates, recovery ratios, and inlet/outlet pressures of pumps were assumed like above. Also, the efficiencies $(\% / 100)$ of the pump and motor were assumed as 0.7 and 0.8 , respectively.

Table 2. Comparative cost of boron reduction by BWRO and IX systems in large SWRO plants. ${ }^{13)}$ (unit: cents $/ \mathrm{m}^{3}$ )

\begin{tabular}{lcc} 
Capital costs & BWRO system system \\
Investment (excl. membranes/resin) & & 1.65 \\
Membranes/resin & 1.23 & 1.04 \\
Insurance and taxes & 0.29 & 0.14 \\
Total capital costs & 0.10 & 2.83 \\
O\&M costs & 1.62 & 0.23 \\
Membrane replacement/resin attrition & & 0.50 \\
Maintenance & 0.56 & 0.18 \\
Overhead & 0.15 & 2.10 \\
Chemicals & 0.18 & 0.32 \\
Power & 1.80 & 0.30 \\
Water losses & 2.25 & 3.63 \\
Total O\&M costs & 1.60 & 6.46 \\
\hline
\end{tabular}


약품을 사용하여 재생폐액이 발생한다는 단점이 있다. CDI 공정의 경우 저농도의 보론을 제거하는데는 적합하지 않았다. 2) 에너지 소비량 측면에서 보면 검토된 세 공정중 IX공정 이 가장 우수한 것으로 분석되었다. RO와 같은 가압형 공정이 아니며 $\mathrm{CDI}$ 처럼 전기를 셀에 인가하는 공정이 아니기 때문에 에너지 소비량이 크지 않았다. $\mathrm{CDI}$ 는 가압형 공정은 아니지 만 셀의 구조적인 특징으로 인해 스케일업시 압력강하가 커질 수 있고 셀에 인가해주는 전기량이 작지 않았다.

3) 시스템 설비 측면에서 보면 RO공정은 분리막 세정 주기 가 다른 공정보다는 길고 약품사용량이 상대적으로 적으며 관련 설비가 단순하며 운전이 용이하다는 장점이 있다. 상대 적으로 $\mathrm{CDI}$ 공정과 $\mathrm{IX}$ 공정은 각각 전극 재생과 수지 재생 주기가 짧아 연속적으로 생산하기 위해서는 교대 운전이 가능 하도록 설비가 구성되어야 하며, 운전 제어 로직이 둘다 단순 하지 않은 단점이 있다.

4) 상기 외에도 역삼투식 해수담수화 공정의 2nd pass로 사 용되기 위해서는 생산수가 사용되는 용도, 약품재생에 따른 환경문제, 설비 비용 등 여러가지 요소들을 복합적으로 고려 해야 한다.

\section{Acknowledgement}

본 결과물은 환경부의 재원으로 한국환경산업기술원의 플랜 트연구사업의 지원을 받아 연구되었습니다(과제번호: 116961). 이에 감사드립니다.

\section{References}

1. K. Park, J. Kim, D. R. Yang, S. Hong, Towards a low-energy seawater reverse osmosis desalination plant: a review and theoretical analysis for future directions, J. Membra. Sci. 595, 117607(2020).

2. L. F. Greenlee, D. F. Lawler, B. D. Freeman, B. Marrot, P. Moulin, Reverse osmosis desalination: water sources, technology, and today's challenges, Water Res., 43, 2317-2348(2009).

3. N. Voutchkov, Desalination Engineering: Planning and Design, McGraw-Hill, New York, US, pp. 413-415(2013).

4. N. Hilal, G. J. Kim, C. Somerfield, Boron removal from saline water: a comprehensive review, Desalination, 273, 23-35(2011).

5. Y. C. Kim, S. Lee, Adsorptive removal of boron from aqueous solutions with selective resins in high-depth fixed-bed columns, Desalin. Wat. Treat. 108, 152-163(2018).

6. M. Qin, A. Deshmukh, R. Epsztein, S. K. Patel, O. M. Owoseni, W. S. Walker, M. Elimelech, Comparison of energy consumption in desalination by capacitive deionization and reverse osmosis, Desalination, 455, 100-114(2019).

7. M. F. Garcia-Soto, E. M. Camacho, Boron removal from industrial wastewaters by ion exchange: an analytical control parameter, Desalination, 181, 207-216(2005).

8. N. Kabay, M. Bryjak, N. Hilal, Boron separation Processes, Elsevier, Amsterdam, Netherland, pp. 199-217(2015).

9. M. F. C. Arias, L. V. I Bru, D. P. Rico, P. V. Galvan, Comparison of ion exchange resins used in reduction of boron in desalinated water for human consumption, Desalination, 278, 244-249(2011).

10. P. Dorji, D. I. Kim, S. Hong, S. Phuntsho, H. K. Shon, Pilot-scale membrane capacitive deionisation for effective bromide removal and high water recovery in seawater Desalination, 479, 114309(2020).

11. S. Seo, H. Jeon, J. K. Lee, G. Kim, D. Park, H. Nojima, J. Lee, S. Moon, Investigation on removal of hardness ions by capacitive deionization (CDI) for water softening applications, Water Res. 44, 2267-2275(2010).

12. H. Vogelesang, An introduction to energy consumption in pumps, World Pumps, January, 28-31(2008).

13. P. Glueckstern, M. Priel, Optimization of boron removal in old and new SWRO systems, Desalination, 156, 219-228(2003).

\section{Declaration of Competing Interest}

The authors declare that they have no known competing financial interests or personal relationships that could have appeared to influence the work reported in this paper.

\section{Authors and Contribution Statement}

\section{Yu Chang Kim}

Department of Environmental Machinery, Korea Institute of Machinery and Materials, Principal Researcher, ORCID (1) 0000-0002-7527-0051: Funding acquisition, Project administration, Resources, Conceptualization, Methodology, Data curation, Data analysis, Writing - original draft, review and editing.

\section{Sungil Lim}

Department of Environmental Machinery, Korea Institute of Machinery and Materials, Senior Researcher, ORCID®0000-00029253-3693: Project administration, Methodology, Data analysis, Visualization, Writing - original draft, review and editing.

\section{Bangwoo Han}

Department of Environmental Machinery, Korea Institute of Machinery and Materials, Principal Researcher, ORCiD (D) 0000-0001 -5780-290X: Resources, Data analysis, Writing - review and editing.

\section{Sang Bok Kim}

Department of Environmental Machinery, Korea Institute of Machinery and Materials, Principal Researcher, ORCID (1) 00000002-6880-2662: Data analysis, Visualization, Writing - review and editing. 


\section{Inyong Park}

Department of Environmental Machinery, Korea Institute of Machinery and Materials, Senior Researcher, ORCID (1) 0000-0003-3464-3250: Data analysis, Visualization, Writing review and editing.

\section{Gunhee Lee}

Department of Environmental Machinery, Korea Institute of Machinery and Materials, Senior Researcher, ORCID (다 0000-0003 -3800-2346: Data analysis, Visualization, Writing - review and editing.

\section{Dae Hoon Park}

Department of Environmental Machinery, Korea Institute of Machinery and Materials, Senior Researcher, ORCiD리 0000-00025886-3330: Methodology, Data analysis, Writing - review and editing.

\section{Keejung Hong}

Department of Environmental Machinery, Korea Institute of Machinery and Materials, Senior Technician, ORCID Dㅜ 0000-00023405-8767: Methodology, Data analysis, Writing - review and editing. 